\title{
Neuroleptic-Induced Catalepsy: Electrophysiological Mechanisms of Functional Recovery Induced by High- Frequency Stimulation of the Subthalamic Nucleus
}

\author{
Bertrand Degos, ${ }^{1}$ Jean-Michel Deniau, ${ }^{1}$ Anne-Marie Thierry, ${ }^{2}$ Jacques Glowinski, ${ }^{2}$ Laurent Pezard, ${ }^{3}$ and \\ Nicolas Maurice ${ }^{1}$ \\ ${ }^{1}$ Institut National de la Santé et de la Recherche Médicale Unité 667 and 2 Unité 114/Chaire de Neuropharmacologie, Collège de France, 75231 Paris Cedex \\ 05, France, and ${ }^{3}$ Centre National de la Recherche Scientifique Unité Propre de Recherche 640 -Laboratoire de Neurosciences Cognitives et Imagerie \\ Cérébrale, Hôpital de la Salpêtrière, 75651 Paris Cedex 13, France
}

\begin{abstract}
High-frequency stimulation (HFS) of the subthalamic nucleus (STN) remarkably alleviates motor disorders in parkinsonian patients. The mechanisms by which STN HFS exerts its beneficial effects were investigated in anesthetized rats, using a model of acute interruption of dopaminergic transmission. Combined systemic injections of SCH-23390 $[R(+)$-7-chloro-8-hydroxy-3-methyl-1-phenyl-2,3,4,5,tetrahydro- $1 H$-3-benzazepine] and raclopride, antagonists of the $\mathrm{D}_{1}$ and $\mathrm{D}_{2}$ classes of dopaminergic receptors, respectively, were performed, and the parameters of STN HFS that reversed the neuroleptic-induced catalepsy were determined in freely moving animals. The effects of neuroleptics and the impact of STN HFS applied at parameters alleviating neuroleptic-induced catalepsy were analyzed in the substantia nigra pars reticulata (SNR), a major basal ganglia output structure, by recording the neuronal firing pattern and the responses evoked by cortical stimulation. Neuroleptic injection altered the tonic and regular mode of discharge of SNR neurons, most of them becoming irregular with bursts of spikes and pauses. The inhibitory component of the cortically evoked response, which is attributable to the activation of the direct striatonigral circuit, was decreased, whereas the late excitatory response resulting from the indirect striatopallido-subthalamo-nigral circuit was reinforced. During STN HFS, the spontaneous firing of SNR cells was either increased or decreased with a global enhancement of the firing rate in the overall population of SNR cells recorded. However, in all of the cases, SNR firing pattern was regularized, and the bias between the trans-striatal and trans-subthalamic circuits was reversed. By these effects, STN HFS restores the functional properties of the circuits by which basal ganglia contribute to motor activity.
\end{abstract}

Key words: substantia nigra pars reticulata; basal ganglia; deep brain stimulation; Parkinson's disease; neuronal activity; dopaminergic transmission

\section{Introduction}

The remarkable efficacy of high-frequency stimulation (HFS) of the subthalamic nucleus (STN) in relieving parkinsonian patients from their motor disabilities (resting tremor, rigidity, and bradykinesia) led STN HFS to become an increasingly used treatment of motor symptoms in the advanced state of Parkinson's disease (Limousin et al., 1995). The neurobiological mechanism by which STN HFS improves the motor state of parkinsonian patients is not yet fully understood (Benabid et al., 2002; Dostrovsky and Lozano, 2002; McIntyre et al., 2004a).

Received March 18, 2005; revised July 5, 2005; accepted July 11, 2005.

This work was supported by Institut National de la Santé et de la Recherche Médicale, by Centre National de la Recherche Scientifique, and by grants from the Ministère de la Recherche et des Nouvelles Technologies (Action Concertée Incitative 02 20410) and the Fondation de France (2002011943). B.D. is the recipient of a grant from the Fondation pour la Recherche Médicale. We thank Anne-Marie Godeheu for excellent histological assistance and Patrick L. Tierney for English correction.

Correspondence should be addressed to Dr. Nicolas Maurice, Institut National de la Santé et de la Recherche Médicale Unité 667, Collège de France, 11 place Marcelin Berthelot, 75231 Paris Cedex 05, France. E-mail: nicolas.maurice@college-de-france.fr.

DOI:10.1523/JNEUROSCI.1056-05.2005

Copyright $\odot 2005$ Society for Neuroscience $\quad$ 0270-6474/05/257687-10\$15.00/0
According to the classic pathophysiological model of Parkinson's disease (Albin et al., 1989; DeLong, 1990), the degeneration of dopaminergic (DA) nigrostriatal neurons generates an overactivity of the glutamatergic neurons of the STN, which innervate the basal ganglia (BG) output nuclei, i.e., the substantia nigra pars reticulata (SNR) and the internal segment of globus pallidus. This leads to an increase in the tonic discharge of BG output nuclei and thereby reinforces the inhibitory influence these GABAergic structures exert on their premotor target nuclei in thalamus and brainstem (Chevalier and Deniau, 1990). Based on the idea that HFS produces a functional inactivation of the stimulated area, it has been first proposed that STN HFS improves parkinsonian motor functions by reducing STN overactivity (Benazzouz et al., 1993). However, recent experimental data reveal that additional mechanisms may occur. (1) In addition to a local inactivation of STN neurons (Beurrier et al., 2001; Magarinos-Ascone et al., 2002; Welter et al., 2004), STN HFS activates STN afferent and efferent pathways leading to distant synaptic inhibitory and excitatory effects in BG output structures (Windels et al., 2000; Salin et al., 2002; Maurice et al., 2003; McIntyre et al., 2004b). (2) The beneficial effects of STN HFS correlate with an activation rather 
than an inhibition of BG output structures (Hashimoto et al., 2003). (3) Finally, the degeneration of DA neurons primarily affects the firing patterns rather than the firing rate of the BG output neurons (Wichmann et al., 1999; Tai et al., 2003) and induces abnormal synchronization and oscillations (Brown et al., 2001; Bar-Gad et al., 2004).

The present study further investigated the mechanisms by which STN HFS alleviates the motor impairments caused by an interruption of DA transmission. For this purpose, the neuroleptic (NL)-induced state of catalepsy in rats, considered to be an animal model of the akinesia and the rigidity seen in Parkinson's disease (Wadenberg, 1996), was used. Catalepsy was induced by acute pharmacological blockade of DA transmission by systemic injection of neuroleptics, and the parameters of STN HFS necessary to reverse the neuroleptic-induced catalepsy were determined. Using these experimental conditions in anesthetized rats, the consequence of DA transmission blockade and the impact of STN HFS in neuroleptic-treated rats were analyzed on both the spontaneous and the cortically evoked patterns of discharge of SNR cells. The pharmacological blockade of DA transmission was preferred to a lesion model to compare in the same SNR neurons the activity changes induced by the neuroleptics and the effects of STN HFS.

\section{Materials and Methods}

Experiments were performed in 50 adult male Sprague Dawley rats weighing 300-330 g (Charles River Laboratories, L'Arbresle, France). All experiments were conducted in accordance with the Policies on the Use of Animals in Neuroscience, as approved by the European Community.

Electrophysiological analysis. Animals (23 rats) were anesthetized with chloral hydrate $(400 \mathrm{mg} / \mathrm{kg}$, i.p., supplemented by continuous intraperitoneal injection of chloral hydrate delivered at a rate of 60 $\mathrm{mg} \cdot \mathrm{kg}^{-1} \cdot \mathrm{h}^{-1}$ using a peristaltic pump) and fixed in a conventional stereotaxic head frame (Horsley-Clarke apparatus; Unimécanique, Epinay-sur-Seine, France). Body temperature was monitored by a rectal thermometer and maintained at $36.5^{\circ} \mathrm{C}$ with a homeothermic blanket (Harvard Apparatus, Kent, UK). Single-unit activity of SNR cells was recorded extracellularly using glass micropipettes (15-20 M $\Omega$ ) filled with a $0.5 \mathrm{M}$ sodium chloride solution containing $1.5 \%$ Neurobiotin (Vector Laboratories, Burlingame, CA). Single neuron action potentials were recorded using the active bridge mode of an Axoclamp-2B amplifier (Molecular Devices, Union City, CA), amplified, and filtered with an AC/DC amplifier (DAM 50; World Precision Instruments, Stevenage, UK) and displayed on a digital oscilloscope (TD 3014 B; Tektronix, Courtaboeuf, France). Nigral neurons were identified as nondopaminergic by their classically defined electrophysiological characteristics: thin spikes (width, $<2 \mathrm{~ms}$ ) and ability to present relatively high-frequency discharges $(>10 \mathrm{~Hz})$ without decrease in spike amplitude (Bunney et al., 1973; Deniau et al., 1978; Guyenet and Aghajanian, 1978). Peristimulus time histograms were generated from 50 stimulation trials. During cortical and STN stimulation, spikes were discriminated from noise and stimulation artifacts on the basis of their amplitude, using the gate function (double threshold) of the discriminator (121 window discriminator; World Precision Instruments) and sampled on-line on a computer connected to a CED 1401 interface using the Spike2 data acquisition program (Cambridge Electronic Design, Cambridge, UK). In a second step, all recordings were checked off-line at a high scale (30 ms per computer screen) to verify that all spikes were correctly sampled and that stimulation artifacts were not taken. As shown Figure 1, spikes were not occulted by the stimulation artifacts because their duration $(0.8-1.1 \mathrm{~ms})$ was much longer than the period during which the amplifier was saturated (0.3-0.45 ms).

Stimulation procedures. The orofacial motor cortex [anteriority from the interaural line (a), $12.5 \mathrm{~mm}$; laterality from the midline (1), $3.8 \mathrm{~mm}$; depth, $1.2 \mathrm{~mm}$ from the cortical surface] and the STN (a, $5.2 \mathrm{~mm} ; 1,2.5$ $\mathrm{mm}$ ) ipsilateral to the recorded SNR were stimulated through bipolar

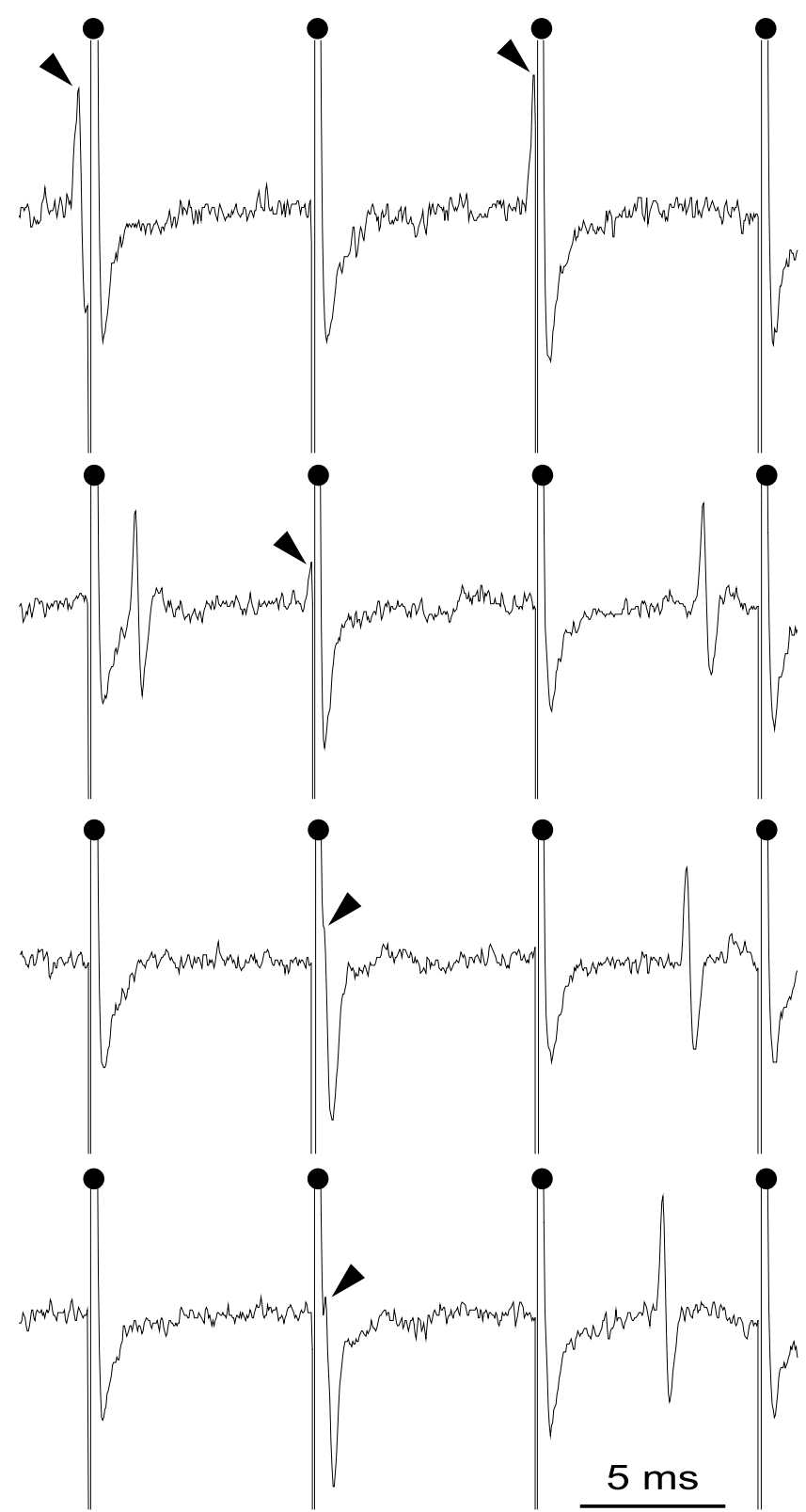

Figure 1. Magnified view of recording traces from an SNR cell during STN HFS. As indicated by the black arrows, action potentials that occurred during the raising or the falling phase of the artifact could be accurately detected because the period during which the amplifier was saturated $(0.44 \mathrm{~ms})$ was much shorter than the mean duration of the spike $(0.8-1.1 \mathrm{~ms})$. Filled dots indicate the stimulation artifacts.

coaxial stainless steel electrodes (diameter, $250 \mu \mathrm{m}$; tip-to-barrel distance, $300 \mu \mathrm{m}$; SNE-100; Rhodes Medical Instruments, Woodlands Hill, CA) positioned stereotaxically according to the atlas of Paxinos and Watson (1986). The recording site in the SNR (a, 3.0-3.4 mm; 1, 2.3-2.6 $\mathrm{mm}$ ) was localized in the sensorimotor division of the nucleus (Deniau et al., 1996), a lateral part of SNR that receives inputs from both the sensorimotor cortex and the stimulated area of the STN (Kolomiets et al., 2003). The positioning of the stimulating electrode within the orofacial motor cortex was precisely defined by the motor response evoked by a brief train of pulses (pulses of $100 \mu$ s width and 10-20 V delivered at a $250 \mathrm{~Hz}$ frequency for $300 \mathrm{~ms}$ ). To ensure the correct positioning of the stimulating electrode into the STN, coordinates of the STN were first determined by recording single neuron responses to stimulation of orofacial motor cortex using glass pipettes; then, the stimulating electrode was positioned at the same coordinates. Multiunit responses to cortical stimulation were recorded through the stimulating electrode for final 
adjustments of electrode positioning. Indeed, as described previously, cortical stimulation evokes characteristic responses in STN cells consisting of two excitatory responses separated by a brief inhibition (Ryan and Clark, 1992; Maurice et al., 1998). Cortical stimulations consisted of pulses of $600 \mu$ s width and $10-20 \mathrm{~V}$ (corresponding to $200-400 \mu \mathrm{A}$ ) delivered at a $1 \mathrm{~Hz}$ frequency. Electrical STN stimulation consisted of pulses of $60 \mu$ s width and $2-5 \mathrm{~V}$ (corresponding to $40-100 \mu \mathrm{A}$ intensity) delivered at $130 \mathrm{~Hz}$. As described previously (Maurice et al., 1999), cortical stimulation evokes characteristic responses in SNR cells consisting of a sequence of excitation-inhibition-excitation. The criterion used to establish the existence of an excitatory response was an increase of $>50 \%$ in the number of spikes compared with the peristimulus frequency for at least three consecutive bins. The amplitude of excitatory responses was quantified by calculating the difference between the number of spikes evoked within the time window of the excitation and the mean number of spikes occurring spontaneously within a similar time window before the stimulation. The duration of an inhibitory response corresponded to the time interval during which no spikes was observed.

Discharge pattern analysis. Spontaneous activity of SNR neurons was sampled by a period of $30 \mathrm{~s}$, and epochs of elevated discharge rate were classified as bursts using a Poisson Surprise analysis according to Legendy and Salcman (1985). This was done using a script written for the Spike2 software. Briefly, this analysis evaluates how improbable any given burst that contains $n$ spikes in a time interval $T$, occurred by chance and computed as follows: $S=-\log p$, where $p$ is the probability that, in a random (Poisson) spike train having the same average spikes rate $r$ as the spike train studied, a given time interval of length $T$ contains $n$ or more spikes. $p$ is given by Poisson's formula, as follows:

$$
p=e^{-r T} \sum_{i=n}^{\infty}(r T)^{i} / i !
$$

where $S$ refers to the Poisson Surprise of the burst (the degree to which the burst surprises a person who expects the spike train to be a Poisson process). In this study, only spike trains with $S \geq 2$ were considered to be bursts.

To quantify the regularity of the neuronal firing and for comparative purpose, we measured for each neuron and for each recording condition an index of regularity that was calculated as the mean ratio between the shortest and longest interspike intervals encountered during four successive time periods of $5 \mathrm{~s}$. The occurrence of rhythmic activity was analyzed for each neuron by performing autocorrelograms (bin size, $20 \mathrm{~ms}$ ) for each recording condition. Cells were classified as oscillatory when the autocorrelogram contained a second oscillation peak that was at least twice the magnitude of the random fluctuation in the autocorrelogram.

Statistical analysis. Results are given as mean \pm SEM. Statistical analysis of SNR discharge patterns observed in control conditions after neuroleptic injection and during STN HFS were evaluated using SigmaStat 3.0 (Systat Software, Erkrath, Germany). The effects of neuroleptics on the spontaneous firing of the overall population of recorded SNR cells were studied using a $t$ test. The effects of neuroleptics on the cells recorded successively in control and neuroleptic condition were analyzed using a paired $t$ test or, when necessary, a Mann-Whitney rank sum test (MW). The pattern of spontaneous and cortically evoked discharges in the same SNR neurons in the three experimental situations (control, under neuroleptics, and during STN HFS under neuroleptics) was compared using either a one-way repeated-measures ANOVA (one-way RM ANOVA), followed by a multiple comparison versus control group (Holm-Sidak method) or a Friedman RM ANOVA on ranks followed by a multiple comparison versus control group (Dunn's method). Finally, when appropriate, STN HFS condition was compared with neuroleptic condition using a paired $t$ test or a Fisher's exact test.

Drug application. To achieve pharmacological interruption of DA transmission, rats received simultaneous systemic injection of dopamine receptor antagonists of both the $\mathrm{D}_{1}$ class $[R(+)$-7-chloro-8-hydroxy-3methyl-1-phenyl-2,3,4,5,-tetrahydro-1 H-3-benzazepine (SCH-23390), $0.5 \mathrm{mg} / \mathrm{kg}$, s.c.] and $\mathrm{D}_{2}$ class [ $S$ - $(-)$-raclopride, $2 \mathrm{mg} / \mathrm{kg}$, i.p.]. Both drugs were obtained from Sigma-Aldrich (Lyon, France) and dissolved in sa- line solution. Doses were selected on the basis of behavioral observations (see Results).

Behavioral tests. The degree of catalepsy resulting from the injection of neuroleptics was assessed using the grid and the bar tests (Hauber and Munkle, 1995). The bar test consisted of positioning the rat's forepaws on a horizontal bar ( $1 \mathrm{~cm}$ diameter) placed at $10 \mathrm{~cm}$ above the ground and measuring the latency for one forepaw to be withdrawn from the bar and touch the floor. The grid test consisted of placing the rat with limbs extended on a wired grid positioned at an angle of $45^{\circ}$ from horizontal and measuring the latency for the rat to attempt to correct this unusual posture. The rats that did not maintain their position on the bar or on the grid after three attempts received a score of $0 \mathrm{~s}$ and were considered noncataleptic. In both tests, the latency cutoff time was set at $60 \mathrm{~s}$.

Stimulation procedures in behaving animals. STN HFS was applied in awake rats through bipolar coaxial stainless steel electrodes (diameter $250 \mu \mathrm{m}$; tip-to-barrel distance, $300 \mu \mathrm{m}$; SNE-100; Rhodes Medical Instruments) bilaterally implanted into the STN. Surgical procedures were conducted under anesthesia induced by injection of pentobarbital (60 mg/kg, i.p.; Ceva Santé Animale, Libourne, France) and maintained by injections of ketamine ( $15 \mathrm{mg} / \mathrm{kg}$, i.m., repeated as needed; Merial, Lyon, France). As described above, correct positioning of the stimulating electrodes into the STN was ensured by extracellular single-unit recording of STN cells using glass micropipettes before implantation of stimulating electrodes. Once the exact position of the STN was determined on both sides, micropipettes were removed and replaced by the stimulating electrodes. Multiunit activity was recorded through these electrodes to adjust their final positioning.

Histological verifications. At the end of electrophysiological experiments, the tips of stimulating electrodes were marked by an electrical deposit of iron ( $5 \mu \mathrm{A}$ anodal, $20 \mathrm{~s})$ and observed on histological sections after a ferri-ferrocyanide reaction. Brains were removed and fixed in a $10 \%$ formalin solution. The localization of the blue points was observed
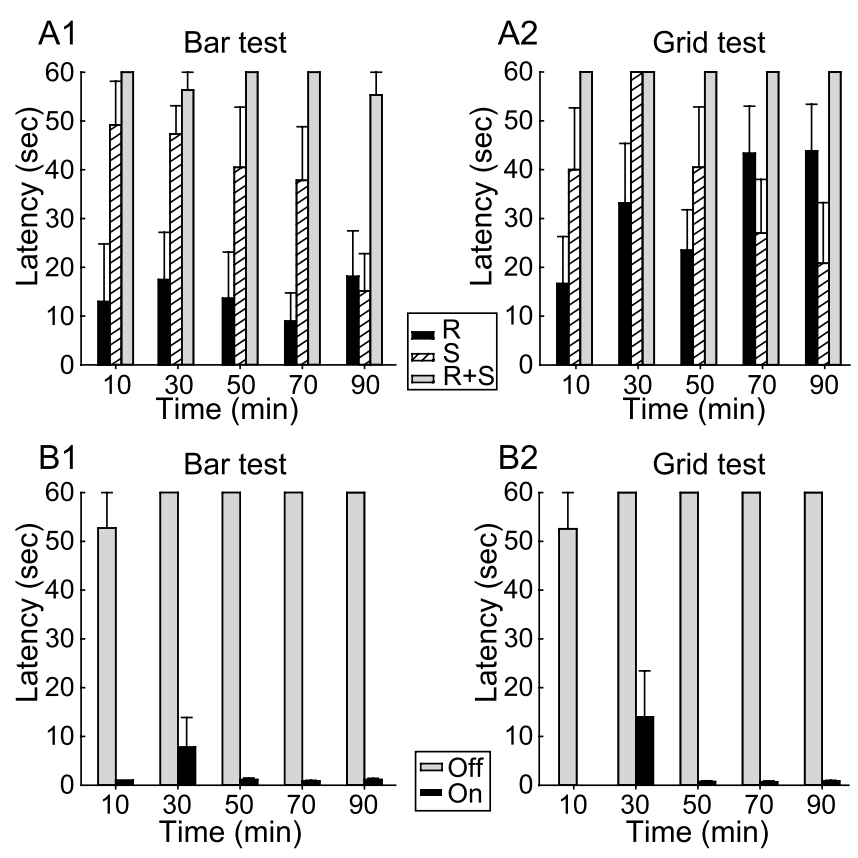

Figure 2. Effect of an acute interruption of dopaminergic transmission on the rat motor behavior and impact of bilateral STN HFS. A1, A2, As assessed using the bar (A1) and grid (A2) tests, simultaneous systemic injection of $S C H-23390(S)$ and raclopride $(R)$, antagonists of the $D_{1}$ and $D_{2}$ classes of dopamine receptors, induced a robust catalepsy completely blocking rat motor behavior. Injection of only one of these neuroleptics resulted in a transient and partial blockade of the motor behavior ( $n=6$ for each condition). B1, B2, STN HFS applied bilaterally readily reversed the neuroleptic-induced catalepsy in both bar (B1) and grid (B2) tests $(n=7)$. Gray bars, STN HFS is turned off (Off); black bars, STN HFS is turned on (On). Time indicates the time from neuroleptic injection. Latency is the time required for the rats to move from their initial position in bar and grid tests (see Materials and Methods). 
on serial frozen sections $(100 \mu \mathrm{m})$ counterstained with safranin. At the end of the chronic stimulation experiments, animals were deeply anesthetized with pentobarbital $(130 \mathrm{mg} / \mathrm{kg}$, i.p.) and perfused intracardiacally with a solution of saline followed by a $0.1 \mathrm{~m}$ phosphate buffer solution, pH $7.4(500 \mathrm{ml})$, containing 4\% paraformaldehyde and $0.1 \%$ glutaraldehyde. Brains were postfixed for $2 \mathrm{~h}$ in a $4 \%$ paraformaldehyde phosphate-buffered solution and stored in a $30 \%$ sucrose phosphate-buffered solution at $4^{\circ} \mathrm{C}$ until sectioned. The localization of the tips of the stimulating electrodes was observed on serial frozen sections $(100 \mu \mathrm{m})$ counterstained with safranin.

\section{Results \\ Neuroleptic-induced catalepsy and reversal by STN HFS}

Unmedicated and unstimulated rats readily moved from their awkward position when placed in the bar and grid test apparatus. In contrast, after a combined systemic injection of antagonists of the $\mathrm{D}_{1}$ (SCH-23390; $0.5 \mathrm{mg} / \mathrm{kg}$, s.c.) and $\mathrm{D}_{2}$ (raclopride; $2 \mathrm{mg} / \mathrm{kg}$, i.p.) classes of dopamine receptors $(n=6)$, a robust cataleptic state was observed, with the rats maintaining their position in the bar and grid test apparatus for at least $55 \mathrm{~s}$ (Fig. $2 \mathrm{~A}$ ). Catalepsy completely blocking rat motor behavior was observed a few minutes after the injections, lasted at least $5 \mathrm{~h}$, and then the animals slowly recovered. After an injection of either raclopride $(2 \mathrm{mg} / \mathrm{kg}$, i.p.; $n=6)$ or SCH-23390 ( $0.5 \mathrm{mg} / \mathrm{kg}$, s.c., $n=$ 6) alone, the rats presented a much less pronounced catalepsy, which was maximal 10-30 min after the injection and reversed shortly thereafter. Therefore, to obtain a long-lasting and reliable effect, combined injection of raclopride and $\mathrm{SCH}-23390$ at the above mentioned doses were used in all of the subsequent behavioral and electrophysiological experiments.

The ability of STN HFS to reverse the neuroleptic-induced catalepsy was tested in nine rats bilaterally implanted with stimulating electrodes into the STN (Fig. 2B). After the systemic injection of neuroleptics, these rats presented a catalepsy similar to that of the rats that did not undergo the surgery. STN HFS (pulses of $60-80 \mu$ s width applied at $130 \mathrm{~Hz}$ ) reliably reversed the catalepsy in seven rats, as assessed by the bar and grid tests. Except for one measure in one rat (scoring $32 \mathrm{~s}$ in the bar test and $58 \mathrm{~s}$ in the grid test at $30 \mathrm{~min}$ after neuroleptic injection), the catalepsy was rapidly reversed with a mean latency of $1.2 \pm 0.2 \mathrm{~s}$ (range, $0-4 \mathrm{~s}$ ) and of $1.6 \pm 0.6 \mathrm{~s}$ (range, $0-15 \mathrm{~s}$ ) in the bar and grid tests, respectively. The most efficient stimulation intensity was determined by slowly increasing the stimulation current from $0 \mu \mathrm{A}$ to the values producing the best functional effect on the rat motor behavior. The stimulation intensities, which consistently reversed the catalepsy were in the range of $40-100 \mu \mathrm{A}(2-5 \mathrm{~V})$. As described previously (Salin et al., 2002; Darbaky et al., 2003), further increasing the stimulation intensity $(>140 \mu \mathrm{A})$ had a deleterious effect. Animals exhibited a progressive head turning and dyskinetic movements of the forepaws. Some attenuation for bias in head position could be obtained by applying slightly different stimulation intensities in the two electrodes. In the two rats in which STN HFS did not reverse the neuroleptic-induced catalepsy, the stimulating electrodes were found to be located in either the anterior part of the SNR or the cerebral peduncle instead of the STN.

\section{Effects of neuroleptics on the spontaneous discharges of SNR cells and impact of the STN HFS}

The effects induced by a combined systemic injection of SCH$23390(0.5 \mathrm{mg} / \mathrm{kg}$, s.c.) and raclopride $(2 \mathrm{mg} / \mathrm{kg}$, i.p. $)$ on the spontaneous discharge of SNR cells was investigated in 23 animals anesthetized with chloral hydrate. Then, the impact of the STN HFS on the firing properties of these cells was analyzed.

In control conditions (before neuroleptic injection), the mean firing frequency of SNR cells was $25.4 \pm 1.3 \mathrm{~Hz}(n=55)$ and most of the neurons exhibited a regular mode of firing (Figs. $3 A, 4 A$ ). Although $33(60 \%)$ of the recorded cells discharged some bursts ( $S$ value $\geq 2)$, burst recurrence was low $(14.9 \pm 2.2$ bursts $/ \mathrm{min}$; $n=246$ bursts) and correlatively, only a limited number of the spikes $(11.4 \pm 1.8 \%)$ emitted by the neurons contributed to bursting activity. The index of discharge regularity, as defined in Materials and Methods, was $0.13 \pm 0.01(n=55$ cells $)$. In some 

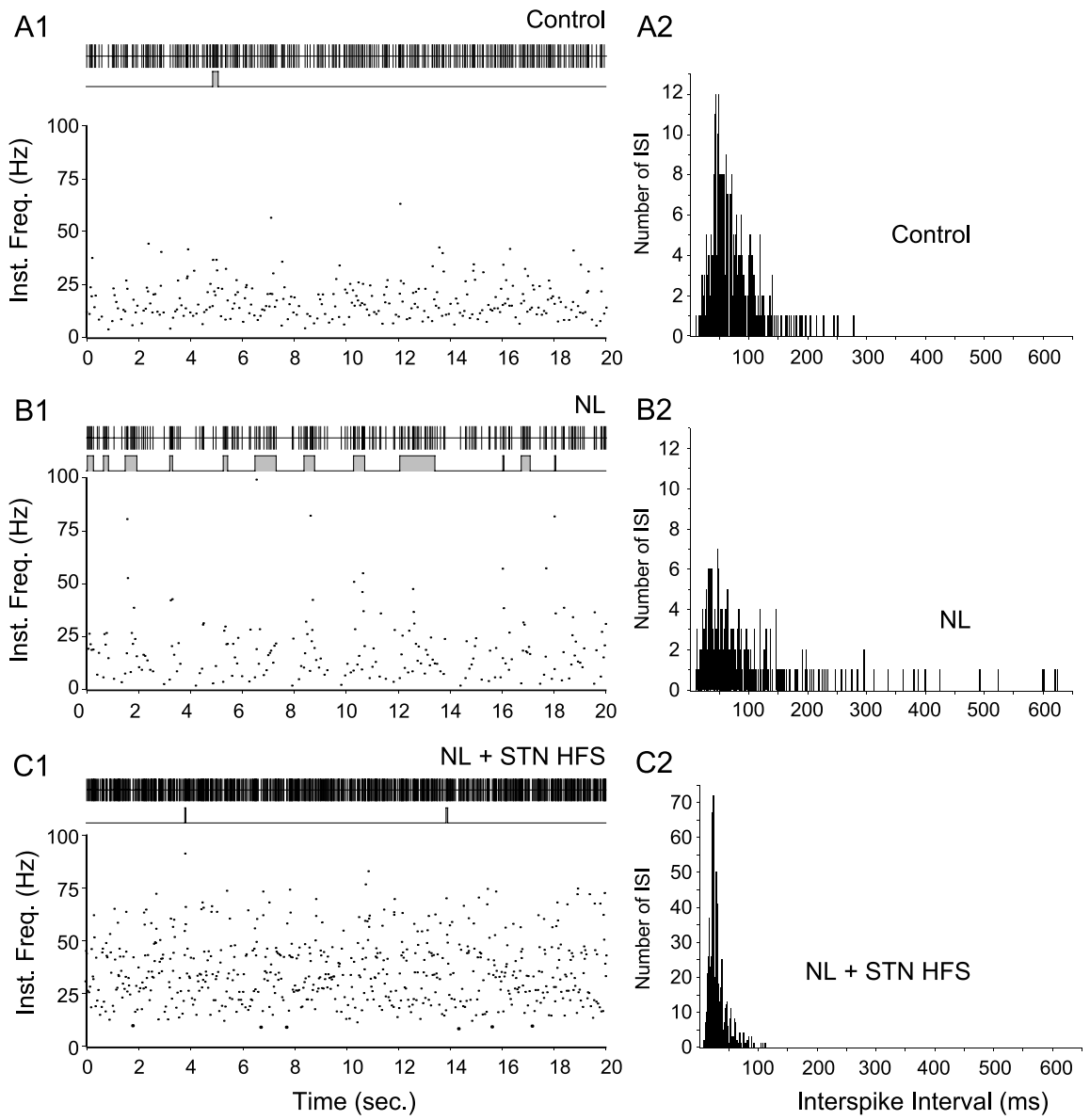

Figure 4. Effect of systemic injection of neuroleptics on the spontaneous activity of an SNR neuron and impact of STN HFS. A case of a neuron whose firing was increased by STN HFS is shown. A1-C2, The spontaneous activity of the same SNR neuron is displayed successively in control condition $(\boldsymbol{A 1}, \boldsymbol{A 2}$; mean discharge rate, $13.7 \mathrm{~Hz})$, after neuroleptic injection $(\boldsymbol{B 1}, \mathbf{B 2}$; mean discharge rate, $9.8 \mathrm{~Hz}$ ), and during STN HFS applied after neuroleptic injection (C1, $\mathbf{C}$; mean discharge rate, $32.8 \mathrm{~Hz})$. In these three situations, the discharge of the cell is represented as a sequence of spikes $(\boldsymbol{A} \mathbf{1}, \boldsymbol{B} \mathbf{1}, \boldsymbol{C} \mathbf{1}$, top $)$ and under the form of instantaneous frequency of discharge (Inst. Freq.; $\boldsymbol{A} \mathbf{1}, \mathbf{B 1}, \mathbf{C 1}$, bottom). Continuous traces in $\mathbf{A 1}, \mathbf{B 1}$, and $\mathbf{C} \mathbf{1}$ (middle) indicate the bursting discharge detected by the Poisson Surprise spike analysis $(S \geq 2)$. A2, B2, $\mathbf{C}$, Histograms display the corresponding interspike intervals (ISIs). Note that neuroleptic injection induced large amplitude oscillations in the firing rate that are reduced during STN HFS applied at parameters that alleviate catalepsy in awake animals.

neurons $(9.1 \%)$, the firing rate displayed a slow rhythmic oscillation $(0.62-1.1 \mathrm{~Hz})$.

After the injection of neuroleptics, the mean firing frequency of SNR cells was not significantly modified $[23.6 \pm 2.1 \mathrm{~Hz}(n=$ 29) under neuroleptics vs $25.4 \pm 1.3 \mathrm{~Hz}(n=55)$ in control condition; $p=0.43$; $t$ test $]$. However, the pattern of discharge was dramatically altered (Figs. $3 B, 4 B$ ). Indeed, most of the recorded SNR neurons $(89.6 \% ; n=26)$ displayed an irregular pattern of firing with bursts of spikes often accompanied by pauses. Compared with the control condition, the mean recurrence of bursts was much higher $(38.3 \pm 3.9$ bursts/min under neuroleptics vs $14.9 \pm 2.2$ in control; $p \leq 0.001 ; \mathrm{MW} ; n=496$ bursts), and both the percentage of spikes contributing to bursts discharges (31.8 \pm $3.3 \%$ under neuroleptics vs $11.4 \pm 1.8 \%$ in control; $p \leq 0.001$; $\mathrm{MW})$ and the mean intraburst firing frequency $(49.0 \pm 1.0 \mathrm{~Hz}$ under neuroleptics vs $40.6 \pm 1.1 \mathrm{~Hz}$ in control; $p \leq 0.05$; MW) were significantly increased. Moreover, reflecting the occurrence of pauses in the discharge of SNR cells, the mean value of the longest interspike interval (measured as the mean of the four longest interspike intervals observed in four successive time periods of $5 \mathrm{~s})$ increased from $136.6 \pm 10.9 \mathrm{~ms}(n=55)$ in control condition to $271.0 \pm 38.3 \mathrm{~ms}(n=30)$ under neuroleptics $(p \leq 0.001 ; \mathrm{MW})$. As a consequence of the occurrence of bursts of spikes and pauses in the neuronal firing, the index of discharge regularity was considerably decreased $[0.06 \pm 0.01(n=30$ cells) under neuroleptics vs $0.13 \pm 0.01$ ( $n=55$ cells) in control condition; $p \leq$ $0.001 ; \mathrm{MW}]$. This reflected the wider range of firing frequencies expressed by the neurons. As illustrated in Figure 5, in 44\% of the neurons, the neuroleptic-induced oscillation in neuronal firing presented a marked rhythmic character $(0.27-1.0 \mathrm{~Hz})$. In the 16 cells that were recorded before and after neuroleptic injection, the changes in the firing pattern of SNR cells usually appeared 5-10 min after neuroleptic injection and reached a stable state after 15-20 min.

The impact of STN HFS on SNR cell activity was analyzed in 24 cells, among which 12 were recorded successively in control conditions, after neuroleptic injection and during STN HFS under neuroleptics (NL + STN HFS) (Figs. 3, 4). STN HFS $(130 \mathrm{~Hz})$ applied in the range of intensity $(40-100 \mu \mathrm{A})$ that we showed to efficiently reverse the neuroleptic-induced catalepsy, produced a decrease in the spontaneous activity in $33.3 \%$ of the SNR cells, an increased activity in $54.2 \%$, and did not modify the firing rate in $12.5 \%$ of the remaining cells. Except for the five excitated cells whose activity was modulated in synchrony with individual stimuli of the HFS (latency range, 1.2-6.1 ms), at the stimulation parameters used in this study, the neuronal discharge of most SNR cells was not locked to individual stimuli of the train. Considering the entire population of SNR recorded cells, the mean firing rate was increased during STN HFS $(23.2 \pm 2.5 \mathrm{~Hz}$ after the neuroleptics vs $36.7 \pm 4.4 \mathrm{~Hz}$ under NL + STN HFS; $p=0.008$; oneway RM ANOVA; $n=24$ ).

The major effect of STN HFS was to regularize the pattern of discharge of SNR cells. Indeed, during STN HFS, there was a significant decrease in the number of neurons exhibiting burst discharges (from $91.7 \%$ under neuroleptics to $62.5 \%$ under NL + STN HFS; $p=0.036$; Fisher's exact test; $n=24$ ). Within the population of neurons still presenting bursts during STN HFS $(n=15)$, there was a decrease in both the percentage of the spikes contributing to bursts (from $29.9 \pm 4.0 \%$ under neuroleptics to $16.6 \pm 3.7 \%$ under NL + STN HFS; $p \leq 0.001$; paired $t$ test $)$ and in the recurrence of bursts (from $34.8 \pm 4.6$ bursts/min under neuroleptics to $22.6 \pm 3.8$ bursts/min during NL + STN HFS; $p=0.006$; paired $t$ test). However, the mean intraburst firing frequency was slightly increased (from $49.9 \pm 1.1 \mathrm{~Hz}$ under neuroleptics to $56.1 \pm 1.5 \mathrm{~Hz}$ during NL + STN HFS; $p=0.007$; $\mathrm{MW}$ ), and no changes were observed in the duration of the bursts (from $261.6 \pm 11.7 \mathrm{~ms}$ under neuroleptics to $250.5 \pm 14.1 \mathrm{~ms}$ during NL + STN HFS; $p=0.522$; MW) (418 bursts analyzed under neuroleptics and 271 during NL + STN HFS). Because 

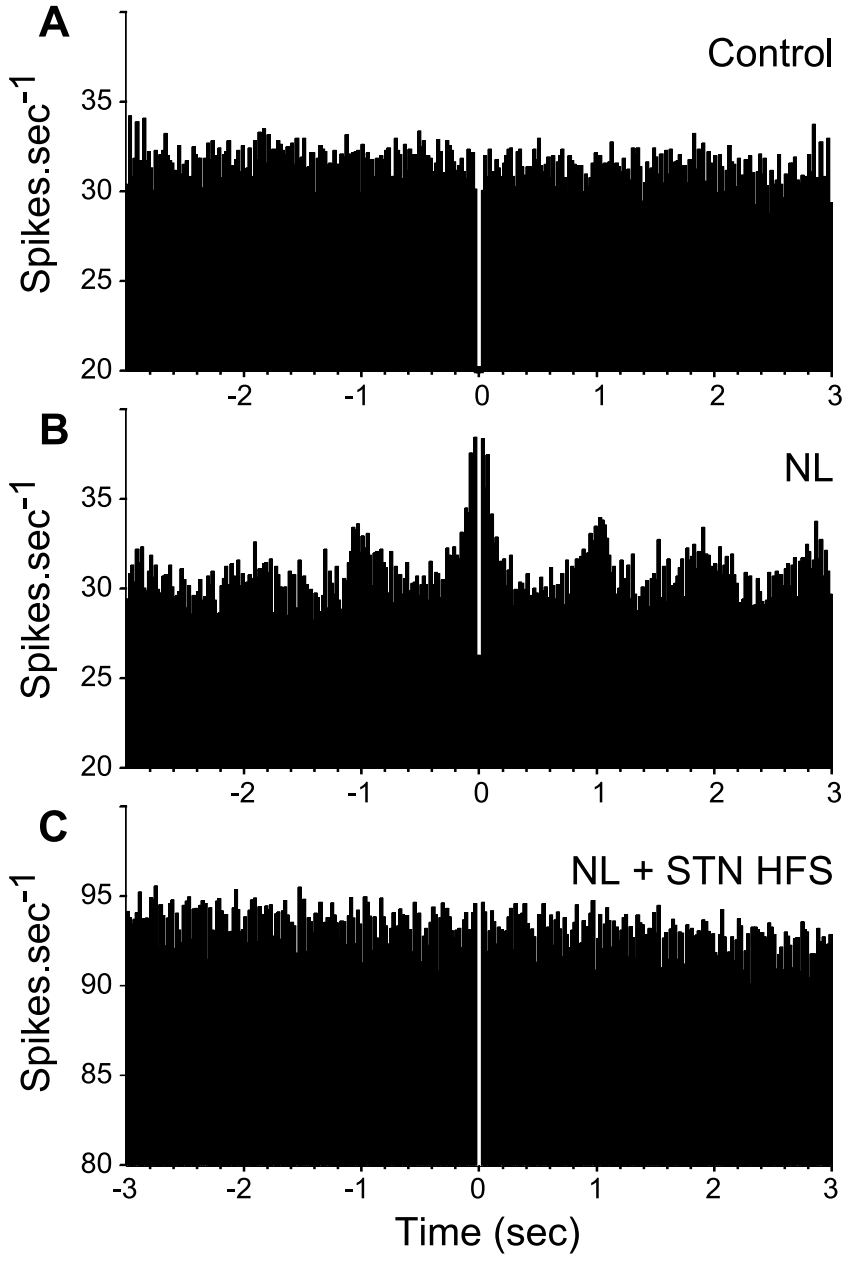

Figure 5. Neuroleptic-induced rhythmic oscillations in SNR cells are suppressed during the STN HFS. A-C, Autocorrelograms were calculated from the same SNR neuron recorded successively in control condition $(\boldsymbol{A})$, after neuroleptic injection $(\boldsymbol{B})$, and during STN HFS (C). The bin size is $20 \mathrm{~ms}$, and the sample duration is $24 \mathrm{~s}$.

STN HFS not only decreased the occurrence of bursts but also shortened the duration of pauses (mean value of the longest interspike intervals decreased from $287.5 \pm 44.0 \mathrm{~ms}$ to $149.0 \pm 21.9$ $\mathrm{ms} ; p \leq 0.001$; Wilcoxon signed rank test), the spike discharge of SNR cells was greatly regularized (Figs. 3C, 4C). Accordingly, the index of discharge regularity passed from $0.05 \pm 0.01$ under neuroleptics to $0.08 \pm 0.01$ during NL + STN HFS $(p \leq 0.001$; paired $t$ test). As illustrated in Figures 3 and 4, the regularizing effect of STN HFS on the discharge pattern of SNR cells was observed in cells that presented either an increase or a decrease of their activity. Finally, in 10 of the 13 SNR cells presenting rhythmic oscillations of their discharge rate under NL, STN HFS abolished these oscillations.

In the 12 neurons that were recorded in control conditions and during STN HFS under neuroleptics, the efficiency of STN HFS in restoring SNR cell firing was further assessed. In the 11 cells whose firing pattern was modified by neuroleptics, nine were significantly corrected during STN HFS (Table 1). Indeed, the index of discharge regularity, which was decreased under neuroleptics recovered to a value sim(NL + STN HFS)]. ilar to that observed in control condition. The mean duration of pauses and the recurrence of bursts, which were significantly increased under neuroleptics also significantly recovered during STN HFS. Finally, the percentage of spikes contributing to burst activity, which was largely increased under NL was significantly decreased by STN HFS, although it remained significantly higher than in control condition. Furthermore, STN HFS abolished neuroleptic-induced oscillations in most of the cells $(75 \% ; n=8)$ (Fig. 5).

\section{Effects of neuroleptics on cortically evoked activity in SNR} cells and impact of STN HFS

The effects induced by a combined systemic injection of SCH$23390(0.5 \mathrm{mg} / \mathrm{kg}$, s.c. $)$ and raclopride $(2 \mathrm{mg} / \mathrm{kg}$, i.p. $)$ on the transfer of cortical information through BG circuitry was analyzed by comparing the responses evoked on single SNR neuron by stimulation of the motor cortex before and after neuroleptic injection. In the control condition, cortical stimulation evoked complex responses in SNR neurons that are composed of an early excitation followed by an inhibition and a late excitation (Figs. $6 A, 7 A$ ). As shown previously (Maurice et al., 1999), the early excitation is attributable to the activation of the "hyperdirect" cortico-STN pathway, the inhibition results from the activation of the direct striatonigral pathway and the late excitation to the activation of the indirect striatonigral pathway that involves the external segment of the globus pallidus (GPe) and the STN.

The effect of neuroleptic injection was tested in 11 SNR neurons that presented a complex response to the stimulation of the motor cortex as assessed by comparing the responses to a sequence of 50 cortical stimulations at $1 \mathrm{~Hz}$. The early excitation was not significantly affected. In contrast, the inhibition and the late excitation were markedly altered. Indeed, the inhibition was reduced, its latency was increased $(15.5 \pm 1.0 \mathrm{~ms}$ under neuroleptics vs $13.5 \pm 0.6 \mathrm{~ms}$ in control; $p<0.01$; paired $t$ test; $n=11$ ), and its duration was shortened $(9.1 \pm 2.0 \mathrm{~ms}$ under neuroleptics vs $15.5 \pm 2.2 \mathrm{~ms}$ in control; $p<0.001$; paired $t$ test; $n=11$ ). In contrast, the late excitation was increased and presented a shortened latency $(25.7 \pm 1.6 \mathrm{~ms}$ neuroleptics vs $30.3 \pm 2.0 \mathrm{~ms}$ in control; $p<0.01$; paired $t$ test; $n=11$ ) and a longer duration $(27.8 \pm 5.4 \mathrm{~ms}$ under neuroleptics vs $12.0 \pm 1.5$ in control; $p<$ 0.001 ; paired $t$ test; $n=11$ ).

To investigate whether STN HFS reverses the neurolepticinduced alterations in the transmission of cortical information through BG circuits, the responses evoked by a sequence of 50 cortical stimulations were analyzed in SNR cells recorded before, after neuroleptic injection, and during NL + STN HFS (Figs. 6, 7 ). In the six SNR neurons that were recorded in these three conditions, STN HFS consistently reversed the neuroleptic-

Table 1. Effects of neuroleptics and impact of STN HFS on the characteristics of discharge of SNR cells

\begin{tabular}{lccc}
\hline$n=9$ & Control & Neuroleptics & NL + STN HFS \\
\hline Rate of discharge (in Hz) & $28.6 \pm 4.6$ & $28.7 \pm 5.3$ & $41.9 \pm 8.6$ \\
Percentage of spikes contributing to burst activity & $9.6 \pm 4.5$ & $37.2 \pm 7.3^{a_{*}}$ & $21.8 \pm 9.1^{a * \#}$ \\
Recurrence of bursts (in bursts/s) & $13.8 \pm 6.5$ & $46.7 \pm 7.6^{b *}$ & $26.0 \pm 8.3$ \\
Mean duration of the four longest pauses (in ms) & $141.8 \pm 22.7$ & $330.9 \pm 107.2^{c *}$ & $157.5 \pm 53.4$ \\
Index of discharge regularity & $0.113 \pm 0.026$ & $0.049 \pm 0.016^{d *}$ & $0.078 \pm 0.019$
\end{tabular}

Each cell $(n=9)$ was recorded in the three conditions: control, under neuroleptics, and during NL + STN HFS. * Statistically different from the control value "Statistically different from the value measured after the neuroleptics injection (paired $t$ test; $p=0.008$ ).

${ }^{a}$ One-way RM ANOVA ( $p \leq 0.001$ ), followed by a multiple comparison versus control group [Holm-Sidak method; $p<0.025$ (neuroleptics), and $p<0.05$

${ }^{b}$ Friedman RM ANOVA on ranks ( $p \leq 0.001$ ), followed by a multiple comparison versus control group (Dunn's method; $p<0.05$ ).

'Friedman RM ANOVA on ranks ( $p=0.016$ ), followed by a multiple comparison versus control group (Dunn's method; $p<0.05$ ).

${ }^{d}$ One-way RM ANOVA ( $p=0.023$ ), followed by a multiple comparison versus control group (Holm-Sidak method; $p<0.025$ ). 

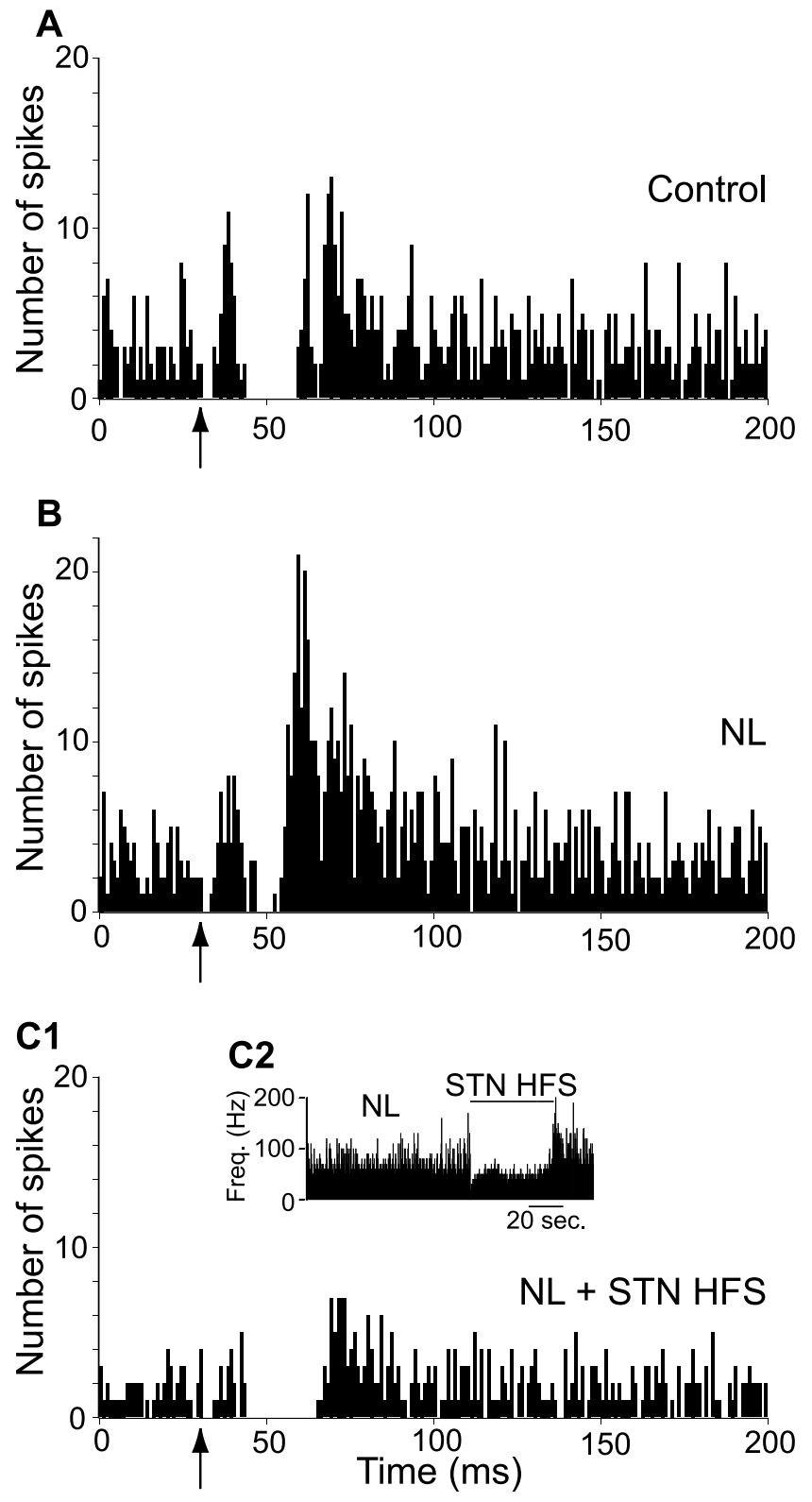

Figure 6. Effect of systemic injection of neuroleptics on the pattern of responses evoked by cortical stimulation in an SNR cell and impact of STN HFS. Case of a neuron inhibited by the STN HFS. $A$, Classical triphasic excitatory-inhibitory- excitatory sequence evoked by stimulation of the orofacial sensorimotor cortex in control condition. $\boldsymbol{B}$, After neuroleptic injection, the inhibitory component of the response presented a marked reduction, whereas the late excitatory component was increased. C1, C2, STN HFS at $2.0 \mathrm{~V}$ produced a marked inhibition of the cell activity $(\boldsymbol{C} 2)$, the inhibitory component of the cortically evoked response was restored and both the early and late excitatory components were decreased (C1). Freq., Frequency. The same number of cortical stimulations $(n=50)$ was applied in $\boldsymbol{A}-\mathbf{C 1}$. The arrows indicate the time of stimulation.

induced alterations. Indeed, as detailed in Table 2, the inhibitory component, which was markedly decreased under neuroleptics, was restored during STN HFS. The increase in the late excitation observed under neuroleptics was reduced during STN HFS. In three cells, these effects were accompanied by a marked decrease (65\%) of the early excitatory component (Fig. 6).

\section{Discussion}

Using the model of neuroleptic-induced catalepsy, the mechanisms by which STN HFS alleviates the motor impairments in-
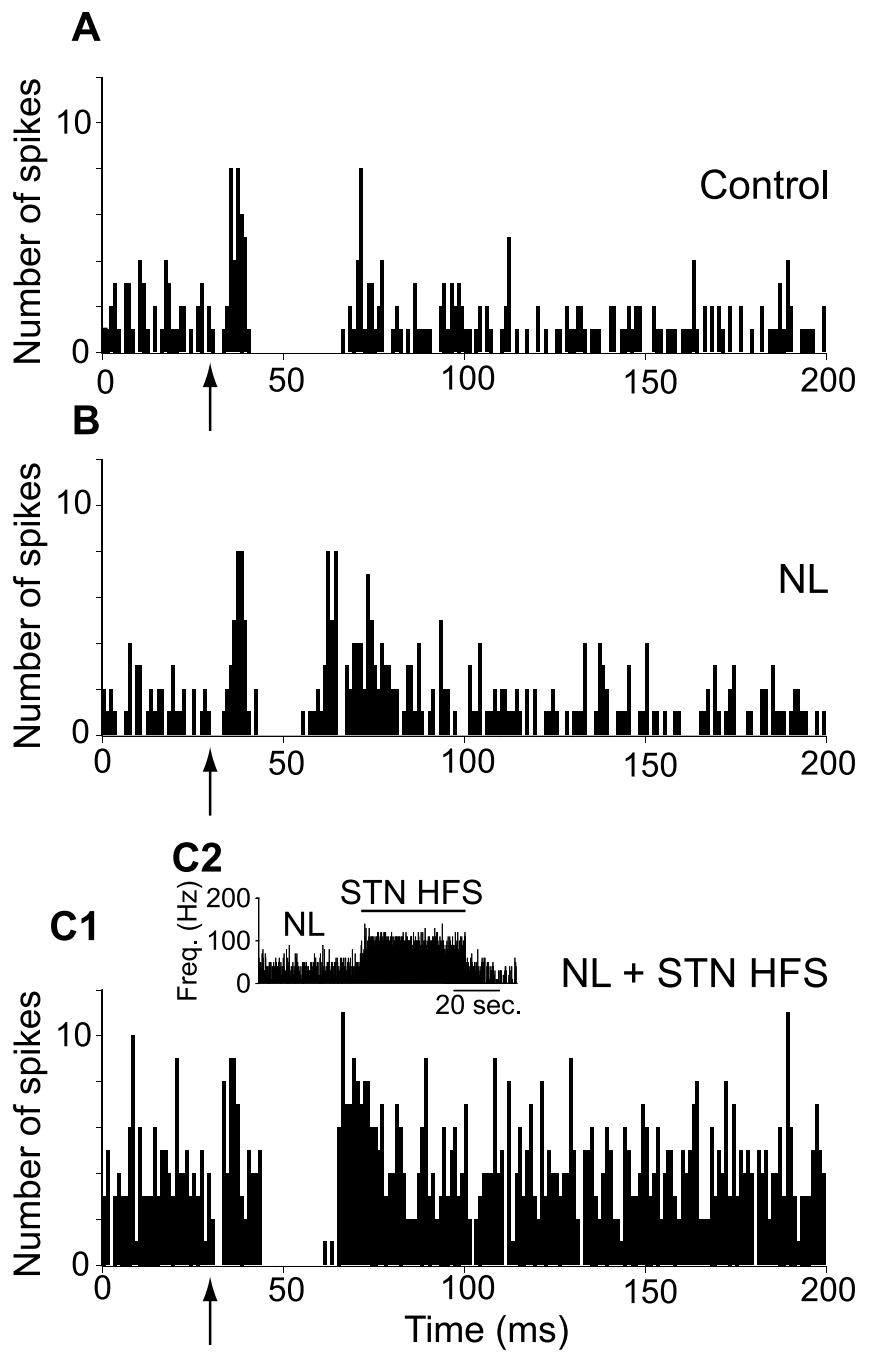

Figure 7. Effect of systemic injection of neuroleptics on the pattern of responses evoked by cortical stimulation in an SNR cell and impact of STN HFS. A case of a neuron activated by STN HFS is shown. $A$, Classical triphasic excitatory-inhibitory- excitatory sequence evoked by stimulation of the orofacial sensorimotor cortex in control condition. $\boldsymbol{B}$, After neuroleptic injection, the inhibitory component of the response presented a marked reduction, whereas the late excitatory component was increased. C1, C2, STN HFS at $5.0 \mathrm{~V}$ under neuroleptics triggered an increase in the spontaneous firing rate of the cell (C2), the inhibitory component was restored, and both the early and late excitatory responses were decreased (C1). Freq., Frequency. The same number of cortical stimulations ( $n=50)$ was applied in $\boldsymbol{A}-\mathbf{C} 1$. The arrows indicate the time of stimulation.

duced by a blockade of DA transmission were investigated. For this purpose, the impact of STN HFS applied at parameters effective to reverse the neuroleptic-induced catalepsy was analyzed on the spontaneous and cortically evoked activity of SNR cells in anesthetized rats. Neuroleptic injection altered the tonic and regular mode of discharge of SNR cells, most of them becoming irregular with bursts of spikes and pauses. Neuroleptics also induced an imbalance between the influence exerted by the direct and indirect striatonigral circuits. During STN HFS, SNR cells were either inhibited or activated, the net effect resulting in a global increased activity of the overall population of recorded cells. In both cases, STN HFS regularized the firing pattern of SNR cells and restored the balance between the inhibitory and excitatory influence exerted by the striatum and the STN on SNR cells, respectively. 


\section{Effect of acute interruption of} dopaminergic transmission

It is generally assumed that striatal neurons projecting to the SNR (direct pathway) preferentially express the $\mathrm{D}_{1}$ class of dopamine receptors, and the striatal neurons of the indirect pathway involving the STN preferentially express the $\mathrm{D}_{2}$ class of dopamine receptors (for review, see Smith et al., 1998). According to the classic pathophysiological model of Parkinson's disease (Albin et al., 1989; DeLong, 1990), interruption of DA transmission would decrease the excitability of the striatal neurons of the direct pathway and increase the excitability of the striatal neurons of the indirect pathway generating an overactivity of BG output neurons. This would reinforce the inhibitory influence that these neurons exert on premotor networks in thalamus and brainstem. Recent advances on the anatomofunctional organization of the BG led to revisit this "striatocentric" model (Chesselet and Delfs, 1996; Levy et al., 1997). Indeed, a large proportion of striatal neurons innervate both the SNR and the GPe via axon collaterals (Kawaguchi et al., 1990; Wu et al., 2000) and coexpress the $D_{1}$ and $D_{2}$ classes of dopamine receptors (Surmeier et al., 1992; Aizman et al., 2000). In addition to the striatum, the other structures of BG receive a DA innervation (Smith et al., 1998). Thus, modifications of the dynamic properties of the BG circuits after DA transmission interruption may result from functional alterations occurring not only in striatum but also at the different levels of the system (Plenz and Kitai, 1999; Ni et al., 2000; Magill et al., 2001).

In the present study, after interruption of the DA transmission by neuroleptic injection, we did not observe an increase in the mean firing rate of SNR cells as predicted by the classical model, but we did observe instead an alteration in their firing pattern. Indeed, the tonic and regular discharge of most of SNR cells became irregular and exhibited high-frequency bursts of spikes and/or pauses. Similar changes in the firing pattern of BG output neurons have been reported in various animal models of PD (Wichmann et al., 1999; Boraud et al., 2002; Tai et al., 2003). Such alterations cannot be adequately explained by the classical model. They likely result from functional alterations in the processing of information at the level the different BG nuclei resulting in a change in the dynamic properties of the network.

Contrary to the modification of the pattern of discharge of BG output neurons, the changes induced by neuroleptics in the transfer of cortical information through the BG circuits were consistent with the striatocentric model. The inhibitory component of the response evoked in SNR cells by cortical stimulation via the direct striatonigral pathway was reduced, whereas the late excitatory component resulting from the activation of the indirect trans-striatal pathway was increased. However, a functional alteration resulting from the blockade of DA transmission at the different levels of the BG circuits cannot be excluded.

\section{Impact of STN HFS on the neuroleptic-induced changes in SNR cells activity}

In the present study, a main effect of STN HFS was to counteract the changes in the pattern of discharge of SNR cells induced by neuroleptics. During STN HFS, the proportion of SNR cells exhibiting bursting activity and the percentage of spikes contributing to bursts were significantly decreased. This regularizing effect was observed in SNR cells whose activity was either increased or decreased by STN HFS. Taking into account all of the recorded neurons, STN HFS applied at an intensity alleviating the neuroleptic-induced catalepsy produced a global increase in the SNR activity. These observations are in agreement with data obtained in dopamine-depleted monkeys, in which the clinical improvements produced by STN HFS correlated with an increased activity in the pallidum (Hashimoto et al., 2003). As proposed previously (Garcia et al., 2003; Hashimoto et al., 2003; Bar-Gad et al., 2004), the present data indicate that the functional improvement induced by STN HFS is likely caused by the regularization of the pattern of discharge of BG output nuclei rather than to a change in their level of firing.

Another major effect of STN HFS revealed by the present study is the restoration of the balance between the inhibitory and excitatory influences exerted by the striatum and the STN, respectively, on SNR cells. Through its excitatory influence, the indirect striatonigral pathway exerts two effects (Kita, 1994; Kitano et al., 1998; Maurice et al., 1999). It regulates the duration of the inhibitory influence exerted by the direct striatonigral pathway on SNR cells and focuses this inhibitory signal onto restricted subpopulations of nigral neurons (Mink and Thach, 1993; Kolomiets et al., 2003). Therefore, by reversing the neuroleptic-induced bias in the direct and indirect striatonigral pathways, STN HFS likely restores the spatiotemporal shaping of BG outflow.

The mechanisms by which STN HFS regularizes the spontaneous discharge of SNR cells and the transmission of cortical information in BG circuits likely involve both local effects within the STN and remote synaptic processes engaged by recruitment of afferent and efferent STN pathways. A functional inactivation of STN neurons resulting from STN HFS is well documented (Beurrier et al., 2001; Magarinos-Ascone et al., 2002; Tai et al., 2003; Welter et al., 2004). Accordingly, the late excitatory response and, in some neurons, the early excitation evoked in SNR cells by cortical stimulation via the activation of the STN were markedly decreased during STN HFS. Such a local inactivation that decreases the transmission of cortical information via the trans-subthalamic circuits likely contributes to restore the balance between the inhibitory striatal input and the excitatory STN input to BG output structures. Moreover, as shown previously, in animal models of PD (Tseng et al., 2001), STN inactivation may also contribute to regularizing the spontaneous discharge of SNR cells. In addition to a local effect within the STN, STN HFS induces remote excitatory and inhibitory synaptic events in BG output nuclei through activation of fiber systems. Interestingly, a normalization of the firing pattern of SNR cells was observed whether the cells were inhibited or excited. This observation stresses a possible contribution of both inhibitory and excitatory synaptic events to the process of functional restoration by STN HFS. 


\section{Functional considerations}

In normal conditions, the SNR exerts a tonic inhibition on premotor nuclei in thalamus and brainstem. During the preparation and execution of goal-directed movements (Sato and Hikosaka, 2002), GABAergic striatonigral neurons phasically inhibit SNR neurons and thus generate a disinhibition of their premotor target nuclei (Chevalier and Deniau, 1990). This disinhibitory process requires that, in resting conditions, SNR neurons display a tonic and regular activity. By contributing to the spatiotemporal shaping of the striatal inhibitory signal, it has been proposed that the trans-subthalamic pathways regulate the amplitude of movements and participate in the selection of motor programs (Mink and Thach, 1993). It is expected that, by altering these two processes, interruption of DA transmission generates a parasitical noise in motor networks and disrupts the spatiotemporal shaping of the disinhibitory process leading to inappropriate motor commands (Chesselet and Delfs, 1996; Boraud et al., 2002; Pessiglione et al., 2005).

Two main explanations have been proposed to account for the beneficial effects induced by STN HFS in PD (Dostrovsky and Lozano, 2002; Vitek, 2002; McIntyre et al., 2004a): (1) a suppression of the overactivity of the BG output structures, thus restoring the functionality of the premotor target nuclei; (2) a reshaping of the spatiotemporal structure of neuronal discharge in STN and BG output nuclei allowing the organization of coherent motor commands (Garcia et al., 2003; Bar-Gad et al., 2004). These present data are consistent with the proposal that the beneficial effects of the STN HFS mainly result from a restoration in the spatiotemporal organization of the discharge of BG output nuclei rather than from a reduction of their overactivity (Hashimoto et al., 2003).

We propose that, through its ability to reshape the firing of SNR cells into a tonic and regular mode and to restore the balance between the trans-striatal and trans-subthalamic pathways, the STN HFS restores the functionality of the disinhibitory mechanism by which the $\mathrm{BG}$ are involved in the organization of movement.

\section{References}

Aizman O, Brismar H, Uhlen P, Zettergren E, Levey AI, Forssberg H, Greengard P, Aperia A (2000) Anatomical and physiological evidence for D1 and D2 dopamine receptor colocalization in neostriatal neurons. Nat Neurosci 3:226-230.

Albin RL, Young AB, Penney JB (1989) The functional anatomy of basal ganglia disorders. Trends Neurosci 12:366-375.

Bar-Gad I, Elias S, Vaadia E, Bergman H (2004) Complex locking rather than complete cessation of neuronal activity in the globus pallidus of a 1-methyl-4-phenyl-1,2,3,6-tetrahydropyridine-treated primate in response to pallidal microstimulation. J Neurosci 24:7410-7419.

Benabid AL, Benazzouz A, Pollak P (2002) Mechanisms of deep brain stimulation. Mov Disord 17 [Suppl 3]:S73-S74.

Benazzouz A, Gross C, Feger J, Boraud T, Bioulac B (1993) Reversal of rigidity and improvement in motor performance by subthalamic highfrequency stimulation in MPTP-treated monkeys. Eur J Neurosci 5:382-389.

Beurrier C, Bioulac B, Audin J, Hammond C (2001) High-frequency stimulation produces a transient blockade of voltage-gated currents in subthalamic neurons. J Neurophysiol 85:1351-1356.

Boraud T, Bezard E, Bioulac B, Gross CE (2002) From single extracellular unit recording in experimental and human Parkinsonism to the development of a functional concept of the role played by the basal ganglia in motor control. Prog Neurobiol 66:265-283.

Brown P, Oliviero A, Mazzone P, Insola A, Tonali P, Di Lazzaro V (2001) Dopamine dependency of oscillations between subthalamic nucleus and pallidum in Parkinson's disease. J Neurosci 21:1033-1038.

Bunney BS, Walters JR, Roth RH, Aghajanian GK (1973) Dopaminergic neurons: effect of antipsychotic drugs and amphetamine on single cell activity. J Pharmacol Exp Ther 185:560-571.

Chesselet MF, Delfs JM (1996) Basal ganglia and movement disorders: an update. Trends Neurosci 19:417-422.

Chevalier G, Deniau JM (1990) Disinhibition as a basic process in the expression of striatal functions. Trends Neurosci 13:277-280.

Darbaky Y, Forni C, Amalric M, Baunez C (2003) High frequency stimulation of the subthalamic nucleus has beneficial antiparkinsonian effects on motor functions in rats, but less efficiency in a choice reaction time task. Eur J Neurosci 18:951-956.

DeLong MR (1990) Primate models of movement disorders of basal ganglia origin. Trends Neurosci 13:281-285.

Deniau JM, Hammond C, Riszk A, Feger J (1978) Electrophysiological properties of identified output neurons of the rat substantia nigra (pars compacta and pars reticulata): evidences for the existence of branched neurons. Exp Brain Res 32:409-422.

Deniau JM, Menetrey A, Charpier S (1996) The lamellar organization of the rat substantia nigra pars reticulata: segregated patterns of striatal afferents and relationship to the topography of corticostriatal projections. Neuroscience 73:761-781.

Dostrovsky JO, Lozano AM (2002) Mechanisms of deep brain stimulation. Mov Disord 17 [Suppl 3]:S63-S68.

Garcia L, Audin J, D’Alessandro G, Bioulac B, Hammond C (2003) Dual effect of high-frequency stimulation on subthalamic neuron activity. J Neurosci 23:8743-8751.

Guyenet PG, Aghajanian GK (1978) Antidromic identification of dopaminergic and other output neurons of the rat substantia nigra. Brain Res 150:69-84.

Hashimoto T, Elder CM, Okun MS, Patrick SK, Vitek JL (2003) Stimulation of the subthalamic nucleus changes the firing pattern of pallidal neurons. J Neurosci 23:1916-1923.

Hauber W, Munkle M (1995) Stimulation of adenosine A2a receptors in the rat striatum induces catalepsy that is reversed by antagonists of $N$-methylD-aspartate receptors. Neurosci Lett 196:205-208.

Kawaguchi Y, Wilson CJ, Emson PC (1990) Projection subtypes of rat neostriatal matrix cells revealed by intracellular injection of biocytin. J Neurosci 10:3421-3438.

Kita H (1994) Physiology of two disynaptic pathways from the sensorimotor cortex to the basal ganglia output nuclei. In: The basal ganglia IV (Percheron G, McKenzie JS, Féger J, eds), pp 263-276. New York, London: Plenum.

Kitano H, Tanibuchi I, Jinnai K (1998) The distribution of neurons in the substantia nigra pars reticulata with input from the motor, premotor and prefrontal areas of the cerebral cortex in monkeys. Brain Res 784:228-238.

Kolomiets BP, Deniau JM, Glowinski J, Thierry AM (2003) Basal ganglia and processing of cortical information: functional interactions between trans-striatal and trans-subthalamic circuits in the substantia nigra pars reticulata. Neuroscience 117:931-938.

Legendy CR, Salcman M (1985) Bursts and recurrences of bursts in the spike trains of spontaneously active striate cortex neurons. J Neurophysiol 53:926-939.

Levy R, Hazrati LN, Herrero MT, Vila M, Hassani OK, Mouroux M, Ruberg M, Asensi H, Agid Y, Feger J, Obeso JA, Parent A, Hirsch EC (1997) Re-evaluation of the functional anatomy of the basal ganglia in normal and parkinsonian states. Neuroscience 76:335-343.

Limousin P, Pollak P, Benazzouz A, Hoffmann D, Le Bas JF, Broussolle E, Perret JE, Benabid AL (1995) Effect of parkinsonian signs and symptoms of bilateral subthalamic nucleus stimulation. Lancet 345:91-95.

Magarinos-Ascone C, Pazo JH, Macadar O, Buno W (2002) Highfrequency stimulation of the subthalamic nucleus silences subthalamic neurons: a possible cellular mechanism in Parkinson's disease. Neuroscience 115:1109-1117.

Magill PJ, Bolam JP, Bevan MD (2001) Dopamine regulates the impact of the cerebral cortex on the subthalamic nucleus-globus pallidus network. Neuroscience 106:313-330.

Maurice N, Deniau JM, Glowinski J, Thierry AM (1998) Relationships between the prefrontal cortex and the basal ganglia in the rat: physiology of the corticosubthalamic circuits. J Neurosci 18:9539-9546.

Maurice N, Deniau JM, Glowinski J, Thierry AM (1999) Relationships between the prefrontal cortex and the basal ganglia in the rat: physiology of the cortico-nigral circuits. J Neurosci 19:4674-4681. 
Maurice N, Thierry AM, Glowinski J, Deniau JM (2003) Spontaneous and evoked activity of substantia nigra pars reticulata neurons during highfrequency stimulation of the subthalamic nucleus. J Neurosci 23:9929-9936.

McIntyre CC, Savasta M, Walter BL, Vitek JL (2004a) How does deep brain stimulation work? Present understanding and future questions. J Clin Neurophysiol 21:40-50.

McIntyre CC, Savasta M, Kerkerian-Le Goff L, Vitek JL (2004b) Uncovering the mechanism(s) of action of deep brain stimulation: activation, inhibition, or both. Clin Neurophysiol 115:1239-1248.

Mink JW, Thach WT (1993) Basal ganglia intrinsic circuits and their role in behavior. Curr Opin Neurobiol 3:950-957.

Ni Z, Bouali-Benazzouz R, Gao D, Benabid AL, Benazzouz A (2000) Changes in the firing pattern of globus pallidus neurons after the degeneration of nigrostriatal pathway are mediated by the subthalamic nucleus in the rat. Eur J Neurosci 12:4338-4344.

Paxinos G, Watson C (1986) The rat brain in stereotaxic coordinates, Ed 2. London: Academic.

Pessiglione M, Guehl D, Rolland AS, Francois C, Hirsch EC, Feger J, Tremblay L (2005) Thalamic neuronal activity in dopamine-depleted primates: evidence for a loss of functional segregation within basal ganglia circuits. J Neurosci 25:1523-1531.

Plenz D, Kitai ST (1999) A basal ganglia pacemaker formed by the subthalamic nucleus and external globus pallidus. Nature 400:677-682.

Ryan LJ, Clark KB (1992) Alteration of neuronal responses in the subthalamic nucleus following globus pallidus and neostriatal lesions in rats. Brain Res Bull 29:319-327.

Salin P, Manrique C, Forni C, Kerkerian-Le Goff L (2002) High-frequency stimulation of the subthalamic nucleus selectively reverses dopamine denervation-induced cellular defects in the output structures of the basal ganglia in the rat. J Neurosci 22:5137-5148.

Sato M, Hikosaka O (2002) Role of primate substantia nigra pars reticulata in reward-oriented saccadic eye movement. J Neurosci 22:2363-2373.
Smith Y, Bevan MD, Shink E, Bolam JP (1998) Microcircuitry of the direct and indirect pathways of the basal ganglia. Neuroscience 86:353-387.

Surmeier DJ, Eberwine J, Wilson CJ, Cao Y, Stefani A, Kitai ST (1992) Dopamine receptor subtypes colocalize in rat striatonigral neurons. Proc Natl Acad Sci USA 89:10178-10182.

Tai CH, Boraud T, Bezard E, Bioulac B, Gross C, Benazzouz A (2003) Electrophysiological and metabolic evidence that high-frequency stimulation of the subthalamic nucleus bridles neuronal activity in the subthalamic nucleus and the substantia nigra reticulata. FASEB J 17:1820-1830.

Tseng KY, Kasanetz F, Kargieman L, Pazo JH, Murer MG, Riquelme LA (2001) Subthalamic nucleus lesions reduce low frequency oscillatory firing of substantia nigra pars reticulata neurons in a rat model of Parkinson's disease. Brain Res 904:93-103.

Vitek JL (2002) Mechanisms of deep brain stimulation: excitation or inhibition. Mov Disord 17 [Suppl 3]:S69-S72.

Wadenberg ML (1996) Serotonergic mechanisms in neuroleptic-induced catalepsy in the rat. Neurosci Biobehav Rev 20:325-339.

Welter ML, Houeto JL, Bonnet AM, Bejjani PB, Mesnage V, Dormont D, Navarro S, Cornu P, Agid Y, Pidoux B (2004) Effects of high-frequency stimulation on subthalamic neuronal activity in parkinsonian patients. Arch Neurol 61:89-96.

Wichmann T, Bergman H, Starr PA, Subramanian T, Watts RL, DeLong MR (1999) Comparison of MPTP-induced changes in spontaneous neuronal discharge in the internal pallidal segment and in the substantia nigra pars reticulata in primates. Exp Brain Res 125:397-409.

Windels F, Bruet N, Poupard A, Urbain N, Chouvet G, Feuerstein C, Savasta M (2000) Effects of high frequency stimulation of subthalamic nucleus on extracellular glutamate and GABA in substantia nigra and globus pallidus in the normal rat. Eur J Neurosci 12:4141-4146.

Wu Y, Richard S, Parent A (2000) The organization of the striatal output system: a single-cell juxtacellular labeling study in the rat. Neurosci Res 38:49-62. 